\title{
Dynamic Friction Parameter Identification Method with LuGre Model for Direct-Drive Rotary Torque Motor
}

\author{
Xingjian Wang, Siru Lin, and Shaoping Wang \\ School of Automation Science and Electrical Engineering, Beihang University, Beijing 100191, China \\ Correspondence should be addressed to Xingjian Wang; wangxj@buaa.edu.cn
}

Received 2 December 2015; Revised 22 February 2016; Accepted 6 March 2016

Academic Editor: Roque J. Saltarén

Copyright (C) 2016 Xingjian Wang et al. This is an open access article distributed under the Creative Commons Attribution License, which permits unrestricted use, distribution, and reproduction in any medium, provided the original work is properly cited.

\begin{abstract}
Attainment of high-performance motion/velocity control objectives for the Direct-Drive Rotary (DDR) torque motor should fully consider practical nonlinearities in controller design, such as dynamic friction. The LuGre model has been widely utilized to describe nonlinear friction behavior; however, parameter identification for the LuGre model remains a challenge. A new dynamic friction parameter identification method for LuGre model is proposed in this study. Static parameters are identified through a series of constant velocity experiments, while dynamic parameters are obtained through a presliding process. Novel evolutionary algorithm (NEA) is utilized to increase identification accuracy. Experimental results gathered from the identification experiments conducted in the study for a practical DDR torque motor control system validate the effectiveness of the proposed method.
\end{abstract}

\section{Introduction}

The torque motor, especially Direct-Drive Rotary (DDR) torque motor, has been widely utilized in modern industry applications and features rotation blockage, soft mechanical properties, and a wide speed range [1,2]. Advantages of the motor include high power density, torque/weight ratio, efficiency, rapid response, and small torque ripple [3,4]. However, designing a high-performance position/velocity tracking controller for the DDR torque motor [5] remains a challenge as multiple factors affecting control precision and dynamic nonlinear friction must be considered [6].

Dynamic friction nonlinearity may be addressed with a properly designed friction compensation controller. Effectiveness of the friction compensation controller is largely dependent on the friction model and accurate friction parameters [7]. The current friction model is divided into two types: the static friction model and the dynamic friction model [8]. The static model reflects the relationship between friction force and the relative movement speed consisting of several distinct parts including static friction, Coulomb friction, viscous friction, and the Stribeck curve effect. Effect of friction, when relative velocity between the two contact surfaces is zero, cannot be described by the static friction model.
The dynamic model features superior practical application value as it reflects the relationship between the friction force and both the speed and displacement, reflecting friction phenomenon more accurately. Primary dynamic friction models are the Dahl model [9], the LuGre model [10, 11], the Leuven model [12, 13], the Generalized Maxwell-Slip (GMS) model $[14,15]$, and two-state friction model [16]. The Dahl model [9] is derived from the original Coulomb friction model that includes the Stribeck effect and the static friction torque [17]. Canudas de Wit et al. combined the Dahl model with the bristles model to propose a new approach referred to as the LuGre friction model $[10,11,18]$. The LuGre model accurately describes the complex process of static and dynamic properties in friction including presliding displacement, memorial friction, variable static friction, viscous friction, and Stribeck effect. The LuGre model describes the asperities between two contact surfaces by elastic bristles, and true nature of dynamic friction is considered as the result of the average deflection of these bristles. In advance of the LuGre model, the Leuven model $[12,13]$, and GMS model, authors of $[14,15$, 19] modeled the hysteresis behavior of the dynamic friction within presliding regime. Two-state dynamic friction model [16] was also proved to be capable of capturing the hysteresis behavior. However, the modeling of the hysteresis behavior 
complicates the friction models significantly and increases the difficulties of implementation in the real-time controls [20]. In addition, the hysteresis behavior is not the essential phenomenon in normal position/velocity control of DDR torque motor. Therefore, the LuGre model is still widely used in motor control systems for dynamic friction compensation.

LuGre model operates based on a group of complex nonlinear functions with six parameters, that is, four static parameters and two dynamic parameters, difficult to identify as coupling exists among the six parameters [21-23]. Difficulty also exists for LuGre parameter identification as the internal state of the model is immeasurable and depends on the previously mentioned unknown friction parameters. Traditional parameter identification methodology is challenged in deriving accurate values of these six parameters in the LuGre model.

A new dynamic friction parameter identification method is proposed in this study for the LuGre model and an identification experiment is conducted for a practical DDR torque motor control system. Static parameters are obtained through a series of constant velocity experiments, while dynamic parameters are obtained by presliding process. Novel evolutionary algorithm [24] (NEA) is utilized to increase identification accuracy and optimization speed by employing Time Variant Mutation (TVM) operator. The proposed method is applied to the practical DDR torque motor control system and the LuGre parameters are obtained by using the proposed identification method. Experimental results validate the effectiveness of the proposed method.

\section{Experimental Setup and Mathematical Modeling}

2.1. Experimental Setup and Modeling of DDR Torque Motor. The experimental setup of DDR torque motor motion control system for dynamic friction parameter identification is first presented (Figure 1).

The torque motor studied is a current-controlled DDR torque motor D143M by Danaher driven by a commercial digital servo amplifier S620 by Danaher. A Heidenhain high-resolution rotary encoder ECN113 with Heidenhain PC counter card IK220 is installed to measure the motor rotary displacement. Rotary velocity can then be calculated by the derivative of rotary displacement signal. Rotary displacement and velocity signals may be utilized here to identify dynamic friction parameters and online estimate friction torque. Original designed real-time control software based on RTX realtime operating system and LabWindows/CVI is applied to control and monitor the torque motor system with sampling frequency selected as $f_{s}=2 \mathrm{kHz}$.

Frequency response bandwidth of the motor amplifier is typically higher than $1000 \mathrm{~Hz}$; however, the mechanical dynamics of the DDR torque motor system generally does not exceed $100 \mathrm{~Hz}$. Disregarding the electrical dynamics of the amplifier in normal operating conditions of the DDR torque motor is then reasonable. Input saturation may then also be ignored when the torque motor operates under normal conditions. The relationship of the electromagnetic torque

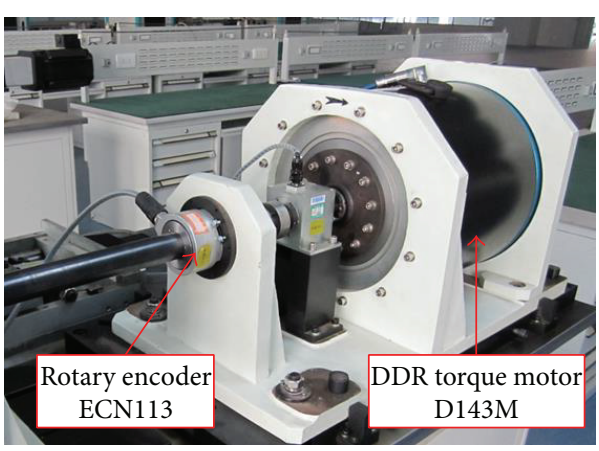

FIGURE 1: Experimental setup of DDR torque motor control system.

$T_{\text {em }}$ and input control voltage $u$ to the motor amplifier, with the above simplifications, may be represented by the following equation [25]:

$$
T_{\mathrm{em}}=K_{m} u
$$

where $K_{m}$ is a proportional coefficient from input control voltage $u$ to electromagnetic torque $T_{\mathrm{em}}$.

Considering friction torque and external disturbances, the dynamics of torque motor may be described as

$$
T_{\mathrm{em}}=K_{m} u=J_{m} \dot{\omega}_{m}+B_{m} \omega_{m}+T_{d}(t)+T_{f},
$$

where $J_{m}$ is total inertia of motor rotator and output shaft; $B_{m}$ is damping coefficient; $\omega_{m}$ is rotational velocity of torque motor; $T_{d}(t)$ represents lumped effect of external disturbances; $T_{f}$ represents the combination of dynamic friction effects and will be formulated later.

Motor parameter identification experiments are then performed to attain nominal values of system parameters. Identification results are $K_{m}=37.7 \mathrm{Nm} / \mathrm{V}, J_{m}=0.045 \mathrm{~kg} \cdot \mathrm{m}^{2}$, and $B_{m}=2.16 \mathrm{Nm} /(\mathrm{rad} / \mathrm{s})$.

2.2. Dynamic Friction Description with LuGre Model. The dynamic friction $T_{f}$ will be formulated in this subsection by utilizing the LuGre friction model, a nonlinear dynamic friction model, widely utilized in mechanical and servo systems. Elastic bristles are employed by the LuGre model to derive asperities between the two contact surfaces on a microscopic scale with the dynamic effects of friction resulting from the average deflection of these bristles (Figure 2). The LuGre model more accurately describes sliding displacement, memorial friction, variable static friction, viscous friction, and Stribeck curve effects synchronously.

The mathematical formulation of LuGre model is as follows [10]:

$$
\begin{gathered}
T_{f}=\sigma_{0} z+\sigma_{1} \dot{z}+\sigma_{2} \omega_{m} \\
\dot{z}=\omega_{m}-\frac{\left|\omega_{m}\right|}{g\left(\omega_{m}\right)} z \\
\sigma_{0} g\left(\omega_{m}\right)=f_{c}+\left(f_{s}-f_{c}\right) e^{-\left(\omega_{m} / v_{s}\right)^{2}},
\end{gathered}
$$

where $z$ is the internal state of LuGre friction model, representing the average deflection of bristles between two 


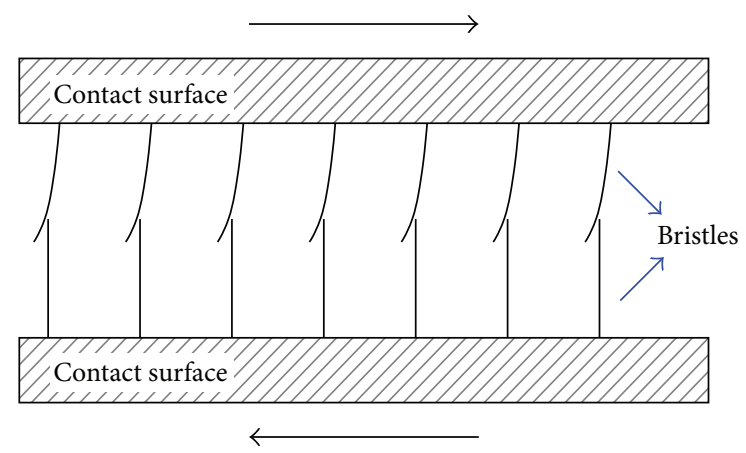

FIgURE 2: Deflection of bristles between two contact surfaces.

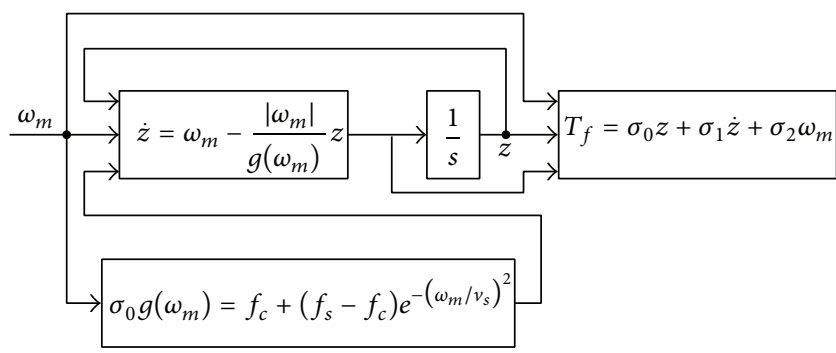

FIGURE 3: The internal relationship of LuGre model.

contact surfaces; $f_{c}, f_{s}, \sigma_{2}$, and $v_{s}$ are four static parameters, representing Coulomb friction, stiction friction, viscous coefficient, and Stribeck velocity, respectively; $\sigma_{0}$ and $\sigma_{1}$ are two dynamic parameters and $\sigma_{0}$ is the average stiffness coefficient of bristles while $\sigma_{1}$ is the average damping coefficient of bristles, respectively; $\sigma_{0} g\left(\omega_{m}\right)$ describes Stribeck effect. According to the mathematical expressions of LuGre model (3)-(5), the internal relationship of LuGre model may be as presented in Figure 3.

The average deflection of bristles will obviously reach a relatively stable state (meaning $\dot{z}=0$ ) when relative velocity exceeds a certain value. The steady-state bristle average deformation $z_{\text {ss }}$ may be described as

$$
z_{\mathrm{ss}}=g\left(\omega_{m}\right) \operatorname{sgn}\left(\omega_{m}\right),
$$

where $\operatorname{sgn}\left(\omega_{m}\right)$ is the sign function and may be expressed as

$$
\operatorname{sgn}\left(\omega_{m}\right)= \begin{cases}1, & \omega_{m}>0 \\ 0, & \omega_{m}=0 \\ -1, & \omega_{m}<0 .\end{cases}
$$

Thus, in the steady state, friction torque may be derived by the following formula:

$$
T_{f_{s}}=\left[f_{c}+\left(f_{s}-f_{c}\right) e^{-\left(\omega_{m} / v_{s}\right)^{2}}\right] \operatorname{sgn}\left(\omega_{m}\right)+\sigma_{2} \omega_{m} .
$$

The LuGre model, as detailed by the LuGre model expression, includes four static parameters and two dynamic parameters. However, identification of these parameters presents a challenge with increased difficulty for identification of dynamic parameters, an issue solved in the following section.

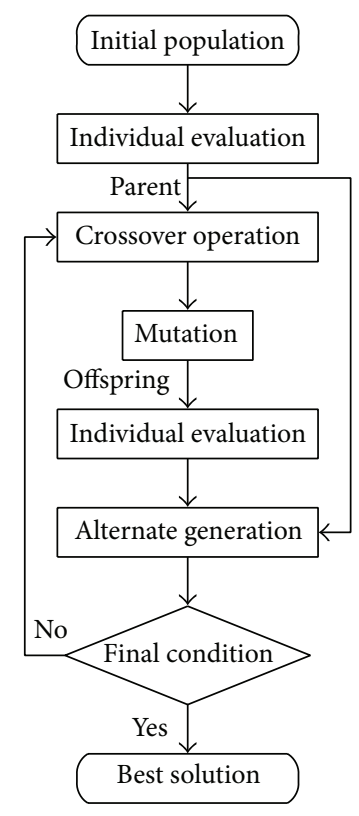

Figure 4: New evolution algorithm flow chart.

\section{NEA Based Parameter Identification Technique}

The NEA based parameter identification technique will be presented in this section to solve the friction parameter identification issue for the LuGre model in the practical DDR torque motor control system.

3.1. Novel Evolutionary Algorithm. Evolutionary algorithm is a widely utilized optimization method $[18,26]$. NEA is the development of evolutionary algorithm by utilizing the dynamic TVM operator to improve algorithm speed and precision [24]. TVM operator may produce rapid changes at initial stages of evolution and precise changes at final stages; therefore, it is believed that TVM could improve the efficiency of NEA and guarantee rapid convergence.

The basic flow chart of NEA is presented in Figure 4 and the specific steps are described as follows.

(1) Initial Population. According to empirical statistics, an initial population $P(0)$ can be selected with $n$ individuals for target variable set $\Omega$. These $n$ individuals are generated by a random function within the desired domain of $\Omega$. Following evaluation of these $n$ individuals with an objective function, the initial population $P(0)$ is divided into $s$ subpopulations with each subpopulation featuring $n / s$ individuals. The initial population $P(0)$ is named as parent population for the next generation.

(2) Individual Evaluation. For target variable set $\Omega$, the individual which makes objective function minimum is selected as the first individual of the $i$ th subpopulation and is named as elite individual $\Theta_{i, \text { mom }}^{t}$ (mother) at $t$ th generation, expressed as

$$
\Theta_{i, \text { mom }}^{t}=\left[f_{c(i, \max )}^{t}, f_{s(i, \max )}^{t}, \sigma_{2(i, \max )}^{t}, v_{s(i, \max )}^{t}\right] .
$$


The average of other individuals then in the $i$ th subpopulation excluding $\Theta_{i \text {,mom }}^{t}$ is defined as mean individual $\Theta_{i \text {,dad }}^{t}$ (father), expressed as

$$
\Theta_{i, \text { dad }}^{t}=\left[f_{c(i, \text { mean })}^{t}, f_{s(i, \text { mean })}^{t}, \sigma_{2(i, \text { mean })}^{t}, v_{s(i, \text { mean })}^{t}\right] .
$$

(3) Crossover Operation. Two offspring $\delta_{i, 1}^{t}$ and $\delta_{i, 2}^{t}$ are generated in this step by crossover operation for each subpopulation as

$$
\begin{aligned}
& \delta_{i, 1}^{t}=\alpha_{1} \Theta_{i, \text { mom }}^{t}+\left(1-\alpha_{1}\right) \Theta_{i, \text { dad }}^{t}=\left[\alpha_{1} f_{c(i, \text { max })}^{t}\right. \\
& +\left(1-\alpha_{1}\right) f_{c(i, \text { mean })}^{t}, \alpha_{2} f_{s(i, \text { max })}^{t} \\
& +\left(1-\alpha_{2}\right) f_{s(i, \text { mean })}^{t}, \alpha_{3} \sigma_{2(i, \text { max })}^{t} \\
& \left.\quad+\left(1-\alpha_{3}\right) \sigma_{2(i, \text { mean })}, \alpha_{4} v_{s(i, \text { max })}^{t}+\left(1-\alpha_{4}\right) v_{s(i, \text { mean })}^{t}\right], \\
& \delta_{i, 2}^{t}=\left(1-\alpha_{1}\right) \Theta_{i, \text { mom }}^{t}+\alpha_{1} \Theta_{i, \text { dad }}^{t}=\left[\left(1-\alpha_{1}\right) f_{c(i, \text { max })}^{t}\right. \\
& +\alpha_{1} f_{c(i, \text { mean })}^{t},\left(1-\alpha_{2}\right) f_{s(i, \text { max })}^{t} \\
& +\alpha_{2} f_{s(i, \text { mean })}^{t},\left(1-\alpha_{3}\right) \sigma_{2(i, \text { max })}^{t} \\
& \left.+\alpha_{3} \sigma_{2(i, \text { mean })},\left(1-\alpha_{4}\right) v_{s(i, \text { max })}^{t}+\alpha_{4} v_{s(i, \text { mean })}^{t}\right],
\end{aligned}
$$

where $\alpha_{k}, k=1,2,3,4$, is a random coefficient in $[0,1]$ and will be recreated for each individual.

For each subpopulation, the elite individual (mother) and the mean individual (father) are chosen and combined. This operation ensures that genes of the elite individual exhibit superior opportunity for the next generation.

(4) Mutation. Mutation is a genetic operator which maintains the genetic diversity and acts as a random variation in a certain range for each subpopulation:

$$
\begin{aligned}
& \delta_{i, 1}^{t^{*}}, \delta_{i, 2}^{t^{*}}=\left[\delta_{f_{c}}^{t^{*}}, \delta_{f_{s}}^{t^{*}}, \delta_{\sigma_{2}}^{t^{*}}, \delta_{v_{s}}^{t^{*}}\right]=\left[\delta_{f_{c}}^{t}+\beta_{1} \lambda(t), \delta_{f_{s}}^{t}\right. \\
& \left.\quad+\beta_{2} \lambda(t), \delta_{\sigma_{2}}^{t}+\beta_{3} \lambda(t), \delta_{v_{s}}^{t}+\beta_{4} \lambda(t)\right],
\end{aligned}
$$

where $\delta_{i, 1}^{t^{*}}, \delta_{i, 2}^{t^{*}}$ are two new offspring generated by the TVM operator and $\beta_{k}, k=1,2,3,4$, is a random coefficient in $(0,1)$ and regenerated for each TVM operation. $\lambda(t)$ is a generating function in TVM operation, given as

$$
\lambda(t)=\left[1-r^{(1-t / T)^{\gamma}}\right],
$$

where $r$ is a random coefficient in $[0,1], T$ is the maximum number of evolutionary generations, and $\gamma$ is a real-valued parameter to determine the degree of dependency.

(5) Individual Assessment. Each offspring is evaluated by the objective function after mutation operation.

(6) Alternate Generation. The $n^{t-1}$ th parental generation and the $n^{t}$ th subgeneration at this stage are integrated together and reordered according to objective function with best $n$ individuals selected as the next generation parent.
(7) Check for Final Condition. Evolution is ended when the final condition is met and the optimal parameter estimates are found; if not, evolution continues.

3.2. Identification of Static Parameters in LuGre Model. The static parameters of LuGre model are obtained by identifying the Stribeck curve of the DDR torque motor. The digital servo amplifier S620 is set to current closed-loop mode with PI controller in this experiment. A speed closed-loop with PI controller is also developed to control motion speed of torque motor in the real-time control software to ensure normal movement of the torque motor without experiencing stickslip phenomenon. The velocity-friction torque curve may be obtained, that is, Stribeck curve, through a series of constant velocity experiments; then the static parameters of LuGre model may be identified by fitting the Stribeck curve.

Considering the constant speed motion control of torque motor and disregarding the disturbance $T_{d}(t)$, the friction in torque motor under constant velocity motion steady state may be described as

$$
T_{f} \approx K_{m} u .
$$

Then, according to (14), the friction torque $T_{f}$ may be calculated during a series of constant speed motions.

A series of constant velocity motion experiments are conducted and the speed values are recorded as $\left\{\omega_{m}\right\}_{i=1}^{N}$; then the corresponding friction torques $\left\{T_{f}\right\}_{i=1}^{N}$ may be calculated according to (14). The number of constant speed experiments in positive rotation direction was chosen in this study to be $N=50$ with 25 experiments in the low-speed range. Identification accuracy of the Stribeck effect was improved by conducting these 25 experiments in low-speed range. The same operations are conducted for negative rotation direction.

By fitting above 100 groups of experimental data, the relationship curve between velocity and friction torque can be obtained, that is, Stribeck curve.

Define the desired static parameter set as

$$
\Omega_{s}=\left[f_{c}, f_{s}, \sigma_{2}, v_{s}\right] .
$$

Then define the fitting error to be

$$
e_{s}\left(\Omega_{s}, \omega_{m}\right)=T_{f}(i)-T_{f s}\left(\Omega_{s}, \omega_{m}, i\right),
$$

where $T_{f}(i)$ is the measured friction torque (14) at the $i$ th constant speed motion experiment; $T_{f_{s}}\left(\Omega_{s}, \omega_{m}, i\right)$ is the calculated friction torque of steady-state LuGre model (8) by using the parameter set $\Omega_{s}$, that is, the friction torque of the Stribeck curve determined by $\Omega_{s}$ at the $i$ th speed point.

Define an objective function of static parameter identification as

$$
J_{s}=\frac{1}{2} \sum\left[e_{s}\left(\Omega_{s}, \omega_{m}\right)\right]^{2} .
$$

By applying NEA optimization and minimizing the objective function $J_{s}$, the Stribeck curve may be identified as demonstrated in Figure 5 with the best estimate of four static parameters, which characterize the Stribeck effect, presented in Table 1. 
TABLE 1: Static parameters identification results.

\begin{tabular}{lcc}
\hline Parameter & Unit & Value \\
\hline$f_{c}$ & $\mathrm{Nm}$ & 6.975 \\
$f_{s}$ & $\mathrm{Nm}$ & 8.558 \\
$\sigma_{2}$ & $\mathrm{Nm} /(\mathrm{rad} / \mathrm{s})$ & 1.819 \\
$v_{s}$ & $\mathrm{rad} / \mathrm{s}$ & $6.109 \times 10^{-2}$ \\
\hline
\end{tabular}

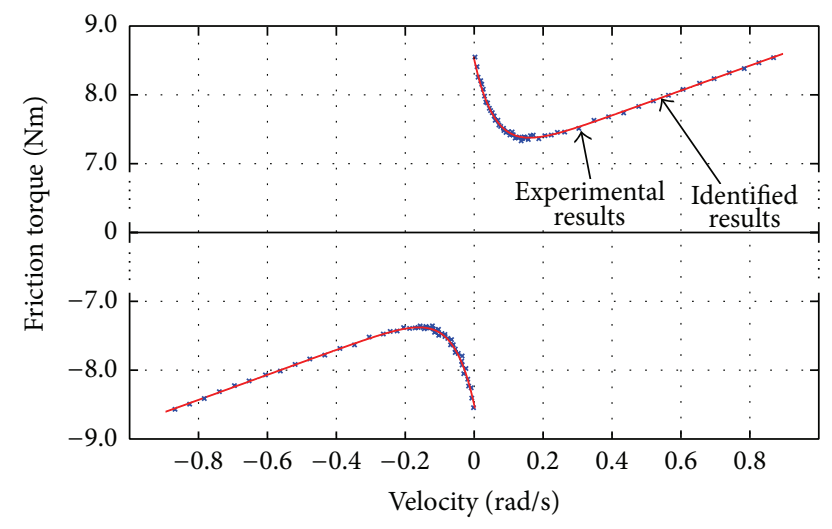

FIGURE 5: Identified Stribeck curve for static parameter identification.

\subsection{Identification of Dynamic Parameters in LuGre Model.}

The process from a static state to a distinct movement between the two contact surfaces is referred to as the presliding process. LuGre dynamic friction model also explains the presliding process. No obvious movement exists between the two contact surfaces in the presliding process, though lack of obvious movement is not indicative of displacement absence, as even miniscule displacement between the two contact surfaces may be considered as bristles deflection. Friction in the presliding process is mainly composed of two parts, that is, $\sigma_{0} z$ and $\sigma_{1} \dot{z}$, according to (3). The presliding process in DDR torque motor may be applied then to identify the two dynamic parameters in LuGre model, that is, $\sigma_{0}$ and $\sigma_{1}$.

The effect of dynamic parameters $\sigma_{0}$ and $\sigma_{1}$ is strengthened in the presliding process in this experiment as the tested torque motor is controlled by the motor driver's inner current loop only. Input voltage signal $u(t)$ to the motor driver is set to be a slowly varying ramp signal:

$$
u(t)=k_{c} t,
$$

where $k_{c}>0$ is a miniscule gradient coefficient and $t$ is time. So under such an input voltage signal, the motor driver will generate a slowly varying electromagnetic torque $T_{\mathrm{em}}$ in the motor. The motor is in the presliding motion state before $T_{\mathrm{em}}$ exceeds the starting torque of torque motor. Experimental data of input voltage signal and output rotary displacement in this presliding process experiment may be utilized for the identification of two dynamic parameters $\sigma_{0}$ and $\sigma_{1}$. Four identified static parameters of LuGre model are also employed for the identification of dynamic parameters.
Dynamic parameters $\sigma_{0}$ and $\sigma_{1}$ are also optimized utilizing the NEA method. Define a desired set of dynamic parameters as

$$
\Omega_{d}=\left[\sigma_{0}, \sigma_{1}\right]^{T} .
$$

Then define the identification error:

$$
e_{d}\left(\Omega_{d}, t_{i}\right)=\theta_{m}\left(t_{i}\right)-\theta_{d}\left(\Omega_{d}, t_{i}\right),
$$

where $\theta_{m}\left(t_{i}\right)$ is an angle output of the torque motor at the $t_{i}$ moment; $\theta_{d}\left(\Omega_{d}, t_{i}\right)$ is an angle output of the parameter identification at the $t_{i}$ moment.

Application of NEA to identify the static parameters allows straightforward estimation of the four initial parameters from the Stribeck curve shape. Estimating the initial value of dynamic parameters $\sigma_{0}$ and $\sigma_{1}$, however, from the presliding process curve of torque motor in the identification process of dynamic parameters is difficult. A more reasonable initial estimate for dynamic parameters is then necessary to optimize dynamic parameters by NEA. Realistically, in the presliding process of the torque motor, the input voltage signal is less than the starting torque of torque motor and changes only gradually; thus it is reasonable to disregard the acceleration of motor rotor and the change rate of LuGre model internal state. System dynamics and LuGre model may be transformed into

$$
\begin{aligned}
k_{m} u & \approx T_{f} \approx \sigma_{0} z \\
\sigma_{0} g\left(\omega_{m}\right) & =f_{s} \\
\dot{z} & =\omega_{m}-\frac{\left|\omega_{m}\right|}{g\left(\omega_{m}\right)} z .
\end{aligned}
$$

Suppose this experiment is starting from zero position (i.e., $z(0)=0$ ), so (23) can be rewritten as

$$
\dot{z}=\frac{d z}{d t}=\omega_{m}-\frac{T_{f}}{f_{s}}\left|\omega_{m}\right|,
$$

where rotary velocity $\omega_{m}$ can be calculated by differencing the rotary displacement signal of the encoder and friction torque may be calculated by (21). A slowly varying ramp signal $u(t)=$ $k_{c} t$ is input to the torque motor system until the motor starts. When $\omega_{m}>0$, the average deflection of the bristles between the contact surfaces may be obtained by integrating (24) as

$$
\begin{aligned}
z(t)= & \theta_{m}(t)-\theta_{m}(0) \\
& +\frac{k_{m} k_{c}}{2 f_{s}}\left(\theta_{m}(t) t+\int_{0}^{t} \theta_{m}(\tau) d \tau\right) .
\end{aligned}
$$

A data group of calculated $z(t)$ can be computed for specified time interval $(0, T)$, and the vectors composed of $z(t)$ are marked as $\mathbf{Z}$ while the vectors composed of $u(t)$ are marked as $\mathbf{U}$. Then the initial value of the dynamic parameters $\sigma_{0}$, by averaging this data group, may be calculated by

$$
\sigma_{0}^{0}=\frac{\mathbf{Z}^{T} \mathbf{U}}{\mathbf{Z}^{T} \mathbf{Z}} .
$$


The initial value of $\sigma_{0}$ as $\sigma_{0}^{0}=2000 \mathrm{Nm} / \mathrm{rad}$ is obtained by applying the above method to the practical torque motor system.

The presliding process of torque motor is selected to estimate the reasonable initial value of other dynamic parameters $\sigma_{1}$. No obvious movement of motor rotor existed in this case; however, there exists a slight deflection of the bristles between two contact surfaces with the average deflection of the bristles equal to the rotary displacement of motor rotor; thus $\theta_{m} \approx z$ and $\omega_{m} \approx \dot{z}$, where $\theta_{m}$ could be measured by the high-resolution rotary encoder and $\omega_{m}$ could be obtained by the differential of $\theta_{m}$. When the torque motor is close to zero position, system dynamics and LuGre model may be expressed as

$$
m \ddot{\theta}_{m}+\left(\sigma_{1}+\sigma_{2}\right) \dot{\theta}_{m}+\sigma_{0} \theta_{m}=u(t) .
$$

Then the transfer function of (27) is

$$
\frac{\theta_{m}(s)}{u(s)}=\frac{1}{m s^{2}+\left(\sigma_{1}+\sigma_{2}\right) s+\sigma_{0}},
$$

where $s$ is a Laplace variable. As reported in [21], it is suitable to describe the combination parameter $\left(\sigma_{1}+\sigma_{2}\right)$ by applying the concept of damping coefficient. The initial value $\sigma_{1}^{0}$ of dynamic parameter $\sigma_{1}$, as a result, may be obtained from (28) as

$$
\sigma_{1}^{0}=2 \xi m \sqrt{\frac{\sigma_{0}}{m}}-\sigma_{2},
$$

where $\xi$ is optimal damping ratio.

Applying the above method to the practical torque motor system, the initial value of $\sigma_{1}$ parameter is obtained as $\sigma_{1}^{0}=$ $40 \mathrm{Nm} \mathrm{s} / \mathrm{rad}$.

The objective function of the dynamic parameter identification is defined as

$$
J_{d}=q_{1} \sum_{i=1}^{N}\left[e_{d}\left(\Omega_{d}, t_{i}\right)\right]^{2}+q_{2} \max \left\{e_{d}\left(\Omega_{d}, t_{i}\right)\right\},
$$

where $q_{1}$ and $q_{2}$ are two weight coefficients and the identification goal is to minimize $J_{d}$. Using the initial values of dynamic parameters $\left(\sigma_{0}^{0} \sigma_{1}^{0}\right)$ and static parameters $\Omega_{s}$ previously obtained, NEA method is also applied to derive the optimal values of dynamic parameters $\sigma_{0}$ and $\sigma_{1}$ by minimizing $J_{d}$.

Experimental and identification results of the presliding process are revealed in Figure 6. According to these results and NEA optimization, the dynamic parameter identification results are $\sigma_{0}=2750 \mathrm{Nm} / \mathrm{rad}$ and $\sigma_{1}=45.2 \mathrm{Nm} \mathrm{s} / \mathrm{rad}$.

\section{Online Friction Estimation Experiments}

In order to further illustrate the proposed parameter identification method, two online friction estimation experiments are carried out, in which the LuGre model with the identified parameters is used. The DDR torque motor is working in the angle control model with a position servo controller.

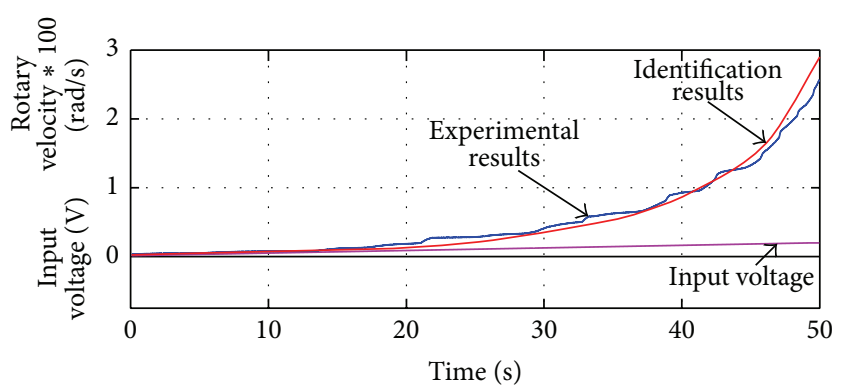

FIGURE 6: Experimental and identification results of presliding process.
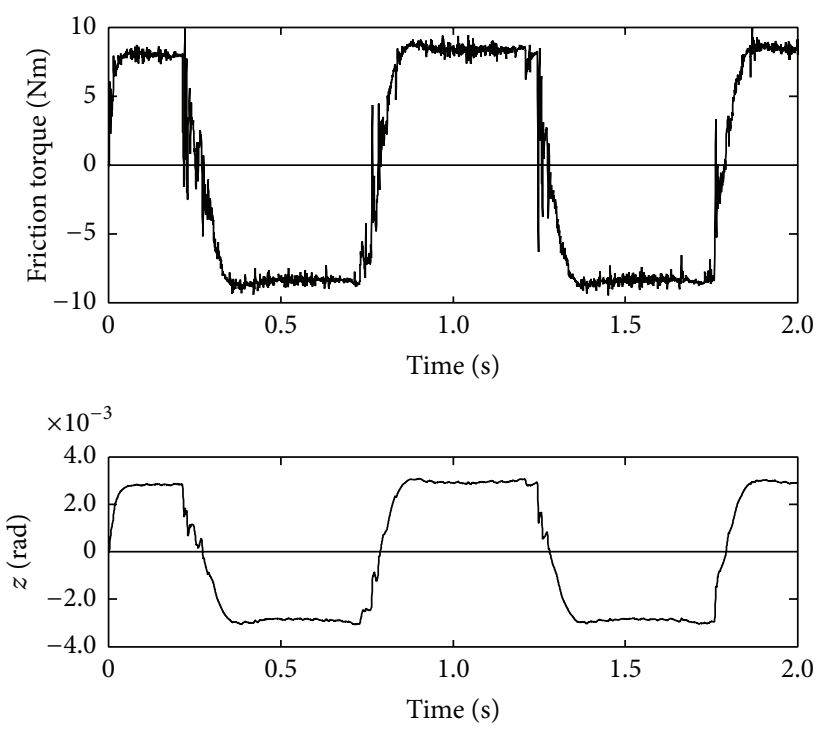

FIGURE 7: Online friction estimation along with internal state in the first experiment.

Two experiments are executed. In the first one, the desired output angle for the DDR torque motor is given by a $1.0 \mathrm{~Hz}$ sinusoidal signal with $0.04 \mathrm{rad}$ amplitude. The online friction estimation results are shown in Figure 7, which is calculated by using the LuGre model with the identified parameters.

In the second experiment, the desired output angle for the DDR torque motor is given by a $0.5 \mathrm{~Hz}$ sinusoidal signal with $0.15 \mathrm{rad}$ amplitude. The online friction estimation results are shown in Figure 8.

These two friction estimation experiments illustrate that the LuGre model is effective to estimate the dynamic friction in the practical system, and this online estimation could be further utilized for the purpose of friction compensation. Experimental results also validate the effectiveness of the proposed parameter identification method for the LuGre model.

\section{Conclusion}

A new dynamic friction parameter identification method is proposed in this study for LuGre model. NEA technique is utilized to increase identification accuracy and an identification experiment is conducted for a practical DDR torque 

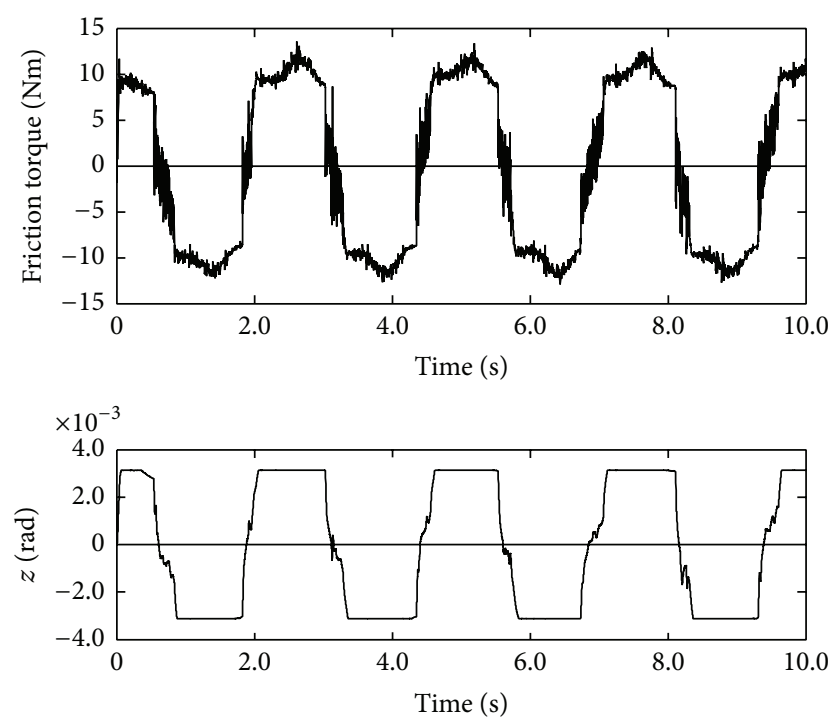

FIGURE 8: Online friction estimation along with internal state in the second experiment.

motor control system. The four static parameters of LuGre model are identified through a series of constant velocity experiments while two dynamic parameters of LuGre model are obtained through the presliding process. Experimental results validate the effectiveness of the proposed method.

\section{Competing Interests}

The authors declare that they have no competing interests.

\section{Acknowledgments}

This work is supported by the National Natural Science Foundation of China (Grant no. 51305011), the National Basic Research Program of China (973 Program) (Grant no. 2014CB046402), and Program 111 of China.

\section{References}

[1] M. Rashed, P. F. A. MacConnell, A. F. Stronach, and P. Acarnley, "Sensorless indirect-rotor-field-orientation speed control of a permanent-magnet synchronous motor with stator-resistance estimation," IEEE Transactions on Industrial Electronics, vol. 54, no. 3, pp. 1664-1675, 2007.

[2] J. Peng, S. Li, and Y. Fan, "Modeling and parameter identification of the vibration characteristics of armature assembly in a torque motor of hydraulic servo valves under electromagnetic excitations," Advances in Mechanical Engineering, vol. 6, Article ID 247384, 2014.

[3] X. Wang, S. Wang, and P. Zhao, "Adaptive fuzzy torque control of passive torque servo systems based on small gain theorem and input-to-state stability," Chinese Journal of Aeronautics, vol. 25, no. 6, pp. 906-916, 2012.

[4] J. Yao, Z. Jiao, and D. Ma, "RISE-based precision motion control of DC motors with continuous friction compensation," IEEE Transactions on Industrial Electronics, vol. 61, no. 12, pp. 70677075, 2014.
[5] Z. Li, D. Fan, and S. Fan, "LuGre-model-based friction compensation in direct-drive inertially stabilization platforms," in Proceedings of the 6th IFAC Symposium on Mechatronic Systems, pp. 636-642, Hangzhou, China, April 2013.

[6] M. Ruderman, "Tracking control of motor drives using feedforward friction observer," IEEE Transactions on Industrial Electronics, vol. 61, no. 7, pp. 3727-3735, 2014.

[7] L. Alvarez, J. Yi, R. Horowitz, and L. Olmos, "Dynamic friction model-based tire-road friction estimation and emergency braking control," Journal of Dynamic Systems, Measurement and Control, vol. 127, no. 1, pp. 22-32, 2005.

[8] Y. Sang, H. Gao, and F. Xiang, "Practical friction models and friction compensation in high-precision electro-hydraulic servo force control systems," Instrumentation Science and Technology, vol. 42, no. 2, pp. 184-199, 2014.

[9] P. R. Dahl, "Measurement of solid friction parameters of ball bearings," in Proceedings of the 6th Annual Symposium on Incremental Motion, Control Systems and Devices, pp. 49-60, University of Illinois, May 1977.

[10] C. Canudas de Wit, H. Olsson, K. J. Astrom, and P. Lischinsky, "A new model for control of systems with friction," IEEE Transactions on Automatic Control, vol. 40, no. 3, pp. 419-425, 1995.

[11] C. Canudas de Wit and P. Lischinsky, "Adaptive friction compensation with partially known dynamic friction model," International Journal of Adaptive Control and Signal Processing, vol. 11, no. 1, pp. 65-80, 1997.

[12] J. Swevers, F. Al-Bender, C. G. Ganseman, and T. Prajogo, "An integrated friction model structure with improved presliding behavior for accurate friction compensation," IEEE Transactions on Automatic Control, vol. 45, no. 4, pp. 675-686, 2000.

[13] V. Lampaert, J. Swevers, and F. Al-Bender, "Modification of the Leuven integrated friction model structure," Institute of Electrical and Electronics Engineers. Transactions on Automatic Control, vol. 47, no. 4, pp. 683-687, 2002.

[14] V. Lampaert, F. Al-Bender, and J. Swevers, "A generalized Maxwell-slip friction model appropriate for control purposes," in Proceedings of the 1st International Conference Physics and Control (PhysCon '03), vol. 4, pp. 1170-1177, IEEE, Saint Petersburg, Russia, August 2003.

[15] F. Al-Bender, V. Lampaert, and J. Swevers, "The generalized Maxwell-slip model: a novel model for friction simulation and compensation," IEEE Transactions on Automatic Control, vol. 50, no. 11, pp. 1883-1887, 2005.

[16] M. Ruderman and T. Bertram, "Two-state dynamic friction model with elasto-plasticity," Mechanical Systems and Signal Processing, vol. 39, no. 1-2, pp. 316-332, 2013.

[17] J. Y. Yoon and D. L. Trumper, "Friction modeling, identification, and compensation based on friction hysteresis and Dahl resonance," Mechatronics, vol. 24, no. 6, pp. 734-741, 2014.

[18] X. Wang and S. Wang, "High performance adaptive control of mechanical servo system with LuGre friction model: identification and compensation," Journal of Dynamic Systems, Measurement and Control, vol. 134, no. 1, Article ID 011021, 2012.

[19] M. Boegli, T. De Laet, J. De Schutter, and J. Swevers, "A smoothed GMS friction model suited for gradient-based friction state and parameter estimation," IEEE/ASME Transactions on Mechatronics, vol. 19, no. 5, pp. 1593-1602, 2014.

[20] L. Lu, B. Yao, Q. Wang, and Z. Chen, "Adaptive robust control of linear motors with dynamic friction compensation using modified LuGre model," Automatica, vol. 45, no. 12, pp. 28902896, 2009. 
[21] R. H. A. Hensen, M. J. G. van de Molengraft, and M. Steinbuch, "Frequency domain identification of dynamic friction model parameters," IEEE Transactions on Control Systems Technology, vol. 10, no. 2, pp. 191-196, 2002.

[22] D. D. Rizos and S. D. Fassois, "Friction identification based upon the LuGre and Maxwell slip models," IEEE Transactions on Control Systems Technology, vol. 17, no. 1, pp. 153-160, 2009.

[23] R. Zglimbea, V. Finca, E. Greaban, and M. Constantin, "Identification of systems with friction via distributions using the modified friction LuGre model," in Proceedings of the 13th Wseas International Conference on Systems-Recent Advances in Systems, pp. 579-584, World Scientific and Engineering Academy and Society, Athens, Greece, July 2009.

[24] K. Watanabe and M. Hashem, Evolutionary Computations: New Algorithms and Their Applications to Evolutionary Robots, Springer, 2012.

[25] X. Wang, S. Wang, and B. Yao, "Adaptive robust torque control of electric load simulator with strong position coupling disturbance," International Journal of Control, Automation and Systems, vol. 11, no. 2, pp. 325-332, 2013.

[26] M. B. Nazir and W. Shaoping, "Optimization based on convergence velocity and reliability for hydraulic servo system," Chinese Journal of Aeronautics, vol. 22, no. 4, pp. 407-412, 2009. 


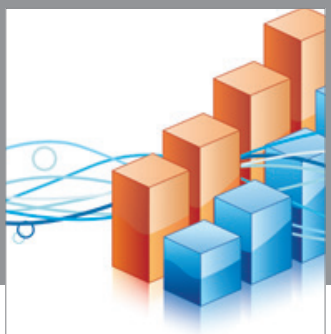

Advances in

Operations Research

vatem alat4

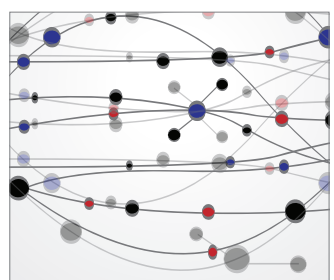

\section{The Scientific} World Journal
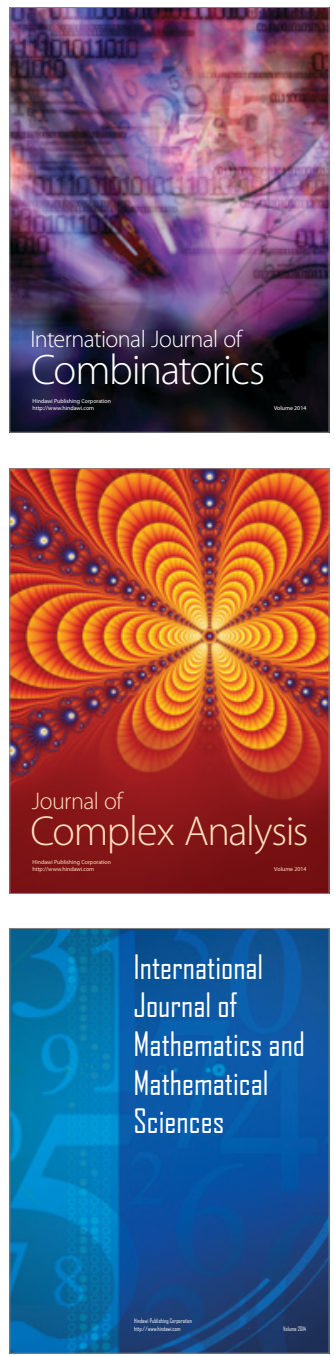
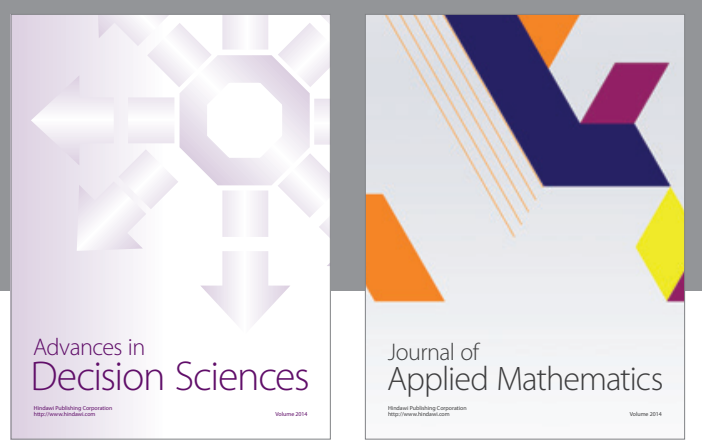

Algebra

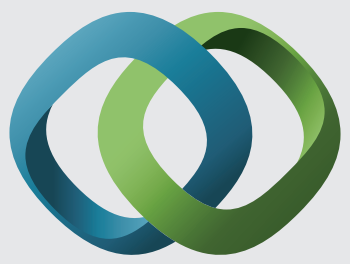

\section{Hindawi}

Submit your manuscripts at

http://www.hindawi.com
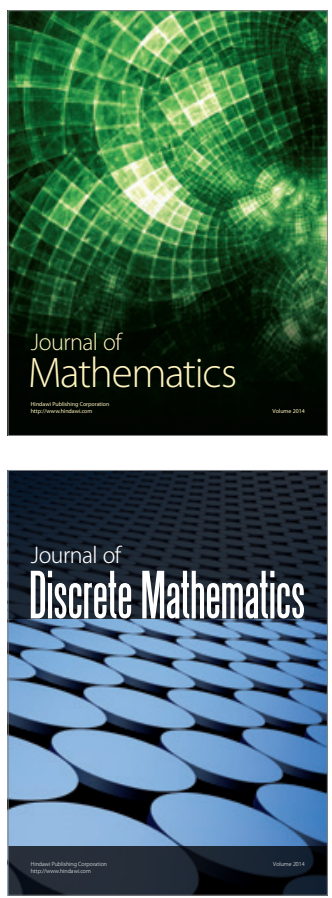

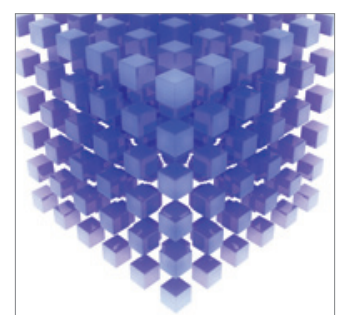

Mathematical Problems in Engineering
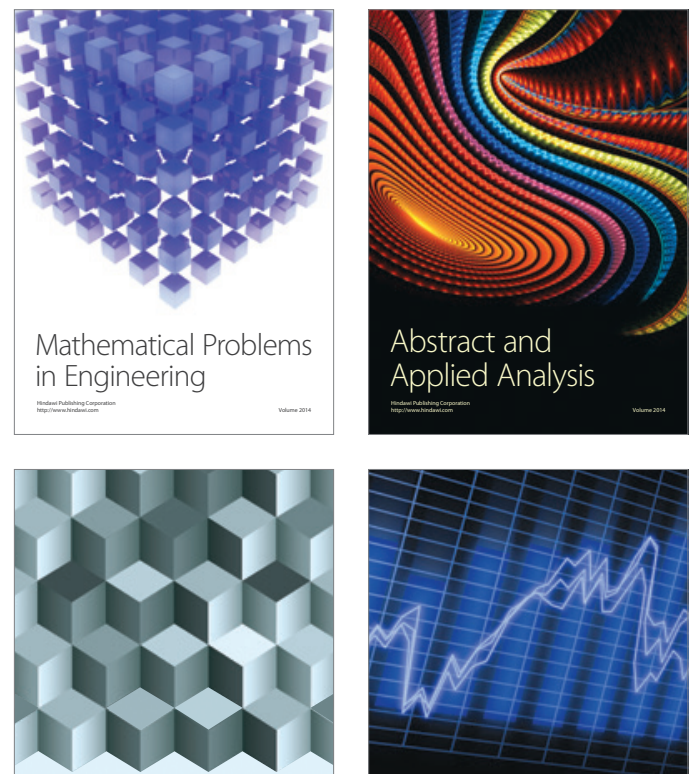

Journal of

Function Spaces

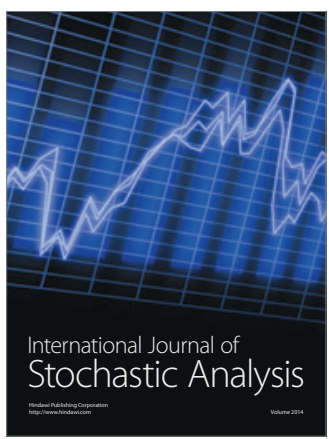

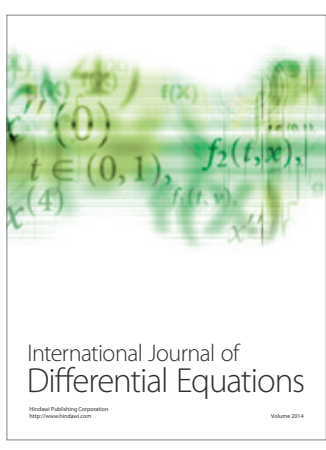
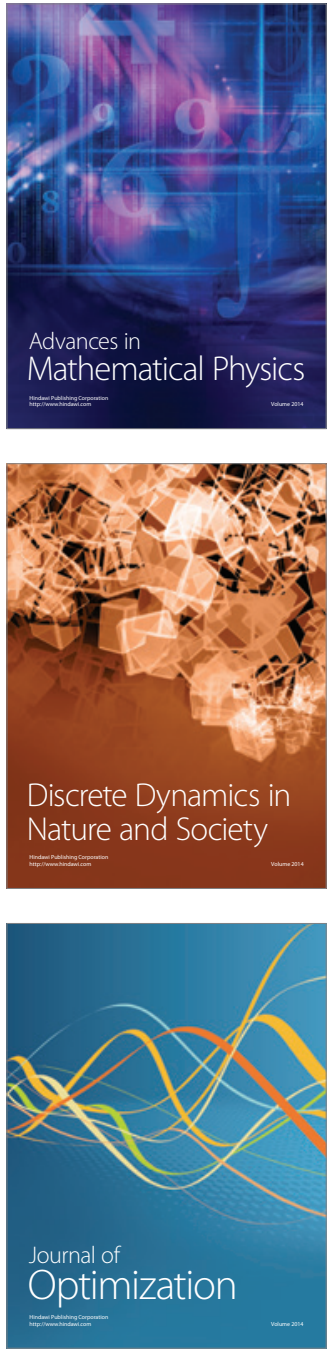